\title{
A prospective study of vaginal trichomoniasis and HIV-1 shedding in women on antiretroviral therapy
}

\author{
Linnet N Masese ${ }^{1 *}$, Susan M Graham ${ }^{2,5,6}$, Ruth Gitau ${ }^{5}$, Nobert Peshu ${ }^{6}$, Walter Jaoko ${ }^{5}$, Jeckoniah O Ndinya-Achola ${ }^{5}$, \\ Kishorchandra Mandaliya ${ }^{7}$, Barbra A Richardson ${ }^{4,8}$, Julie Overbaugh ${ }^{8}$ and R Scott McClelland 1,2,3,5
}

\begin{abstract}
Background: Trichomonas vaginalis has been associated with increased vaginal HIV-1 RNA shedding in antiretroviral therapy (ART)-naïve women. The effect of trichomoniasis on vaginal HIV-1 shedding in ART-treated women has not been characterized. We tested the hypothesis that $T$. vaginalis infection would increase vaginal HIV-1 RNA shedding in women on ART, and that successful treatment would reduce vaginal HIV-1 RNA levels.

Methods: We conducted a prospective cohort study including monthly follow-up of 147 women receiving ART in Mombasa, Kenya. Those with $T$. vaginalis infection, defined by the presence of motile trichomonads on vaginal saline wet mount, received treatment with single dose metronidazole $(2 \mathrm{~g})$. Test of cure was performed at the next monthly visit. Using the pre-infection visit as the reference category, we compared detection of vaginal HIV-1 RNA before versus during and after infection using generalized estimating equations. A cut-off of 100 HIV-1 RNA copies/ swab was used as the lower limit for linear quantitation.
\end{abstract}

Results: Among 31 women treated for trichomoniasis, the concentration of vaginal HIV-1 RNA was above the limit for quantitation before, during, and after T. vaginalis infection in 4 (13\% [95\% Cl 4\% - 30\%]), 4 (13\% [95\% Cl 4\% $30 \%]$ ), and 5 (16\% [95\% confidence interval \{Cl\} 5\% - 34\%]) women respectively. After adjusting for potential confounding factors, we could detect no difference in the likelihood of detecting vaginal HIV-1 RNA before versus during infection (odds ratio [OR] 1.41,95\% Cl $0.23-8.79, \mathrm{p}=0.7$ ). In addition, detection of HIV-1 RNA was similar before infection versus after successful treatment (OR 0.68, 95\% Cl $(0.13-3.45), \mathrm{p}=0.6$ ).

Conclusion: Detection of vaginal HIV-1 RNA during ART was uncommon at visits before, during and after T. vaginalis infection.

Keywords: Trichomonas vaginalis, vaginal infection, antiretroviral therapy, HIV-1, women, Africa

\section{Background}

In sub-Saharan Africa, transmission of HIV-1 is predominantly heterosexual [1]. The risk of transmission is likely related to the concentration of virus in genital mucosal secretions, suggesting that reducing genital HIV-1 shedding may reduce infectivity in seropositive individuals $[2,3]$. Clinical studies provide strong evidence that antiretroviral therapy (ART) leads to rapid and sustained suppression of genital HIV-1 shedding [3,4]. However, this suppression is incomplete [4,5], and persistent genital

\footnotetext{
* Correspondence: linnet@uw.edu

'Department of Epidemiology, Box 357236, University of Washington, Seattle, Washington 98195, USA

Full list of author information is available at the end of the article
}

HIV-1 replication may reflect ongoing risk of transmitting the virus even in individuals on treatment [3].

Trichomonas vaginalis infection is highly prevalent in many parts of the world. Among HIV-1 positive individuals, infection with $T$. vaginalis is associated with higher genital HIV-1 levels [6,7]. Successful treatment of trichomoniasis reduces genital HIV-1 levels in antiretroviralnaïve women [7] and men [6,8]. Antiretroviral therapy decreases genital shedding of HIV-1, but there is some evidence that shedding may still be increased in the presence of genital tract infections. For example, a study in HIV-1 seropositive men on ART demonstrated that gonococcal urethritis may activate local genital HIV-1 replication [9].

It is not known whether vaginal trichomoniasis increases HIV-1 shedding in women on ART, or whether

\section{Biomed Central}


treatment of this infection in patients on ART will decrease HIV-1 shedding, potentially decreasing infectivity [10]. To address these questions, we prospectively evaluated the effect of $T$. vaginalis infection on genital HIV-1 shedding in women on ART.

\section{Methods}

\section{Participants}

This study was conducted between March 2004 and December 2008 among HIV-1-seropositive women between 18 and 45 years old in Mombasa, Kenya. The participants were recruited from within a larger cohort of female sex workers in Mombasa [11]. Women eligible for ART initiated a first-line regimen of stavudine or zidovudine, lamivudine, and nevirapine, as recommended by the World Health Organization (WHO) and the Kenyan Ministry of Health Guidelines at the time [12]. All participants gave written informed consent. The study was approved by the ethical review committees of the Kenya Medical Research Institute, the University of Washington, and the Fred Hutchinson Cancer Research Center.

\section{Clinic procedures}

Participants in the ART cohort were asked to return for monthly follow-up visits. During each visit, study nurses completed a standardized interview covering medical, gynecological, and sexual history. The study physician performed a general physical examination and pelvic speculum examination with collection of specimens for laboratory diagnosis of genital tract infections. A Dacron swab was used to collect vaginal secretions for HIV-1 RNA quantitation by placing the swab firmly on the vaginal wall and rolling 3 times between the fingertips. The swab was then placed into a cryovial with freezing medium (70\% RPMI, 20\% fetal calf serum, and 10\% dimethyl sulfoxide with added penicillin, streptomycin, and amphotericin B). Genital samples collected for HIV-1 RNA viral load were stored at $-70^{\circ} \mathrm{C}$ until they were shipped on dry ice to the Fred Hutchinson Cancer Research Center in Seattle for testing. Blood samples were collected every three months for CD4 lymphocyte count.

\section{Treatment of vaginal infections}

Women with symptomatic vaginal conditions (vaginal discharge, itching, or burning) at an examination visit were treated syndromically according to WHO and Kenyan Ministry of Health Guidelines (oral metronidazole 2 $\mathrm{g}$ as a single dose combined with clotrimazole $100 \mathrm{mg}$ intravaginal pessaries nightly at bedtime for 7 nights) [13]. All genital specimens were obtained prior to provision of treatment. Patients were asked to return one week after each examination visit for laboratory results. At the results visit, additional treatment was provided if indicated based upon laboratory findings. Those with
T. vaginalis infection received treatment with single dose oral metronidazole $(2 \mathrm{~g})$ only if metronidazole was not dispensed at the examination visit. Samples collected one month post-treatment were used to confirm cure. Women with persistent $T$. vaginalis infection were retreated, and then re-evaluated at the next monthly visit. Participants whose $T$. vaginalis infection resolved after treatment (including retreatment) were included in this study.

\section{Laboratory methods}

HIV-1 serostatus was determined by ELISA (Detect HIV1/ 2, BioChem Immunosystems, Montreal, Canada). Positive tests were confirmed using a second ELISA (Recombigen, Cambridge Biotech, Worcester, Massachusetts, USA). Quantitation of CD4 lymphocytes was performed using a manual system (Cytosphere, Coulter, Hialeah, Florida, USA) from March 2004 until October 2004, and thereafter by an automated method (FACS Count, Becton Dickinson, Forest Lakes, New Jersey, USA). HIV-1 RNA quantitation was performed using a Gen-Probe viral load assay on vaginal samples (Gen-Probe, San Diego, California, USA) [14].

Vaginal saline wet mounts were examined microscopically at 40X power for the presence of motile T. vaginalis parasites and yeast cells or hyphae. Vaginal Gram-stained slides were evaluated for bacterial vaginosis (BV) using Nugent's criteria [15]. Bacterial vaginosis was defined as a Nugent's score of 7-10. Culture for Neisseria gonorrhoeae was performed on modified Thayer-Martin media (Difco BD Diagnostics, Oxford, UK). Endocervical samples were also tested for the presence of N. gonorrhoeae and Chlamydia trachomatis by transcription mediated amplification using the Aptima GC/CT Detection System (Gen-Probe, San Diego, California, USA). The presence of sperm in the genital tract was determined by microscopic examination of Gram stained slides of cervical and vaginal secretions.

\section{Statistical analysis}

Visits before, during and after successful treatment of $T$. vaginalis infection were included in this analysis. Women with concurrent cervical infections were excluded because previous studies demonstrate that cervical infections may influence cervicovaginal HIV-1 shedding $[16,17]$. We also excluded episodes in which co-infection with both yeast and $T$, vaginalis were present. Cases with concurrent BV were not excluded, as BV commonly coexists with $T$. vaginalis, and our prior prospective studies have not shown a decrease in HIV-1 RNA shedding when women are treated for BV [7]. For this analysis, only treated episodes of $T$. vaginalis infection that were followed by a visit with cure were included. For women with more than 1 consecutive visit with $T$. vaginalis infection, only the first visit with trichomoniasis was included in the analysis. 
Our a priori sample size calculation was based on the assumption that the majority of women with a genital infection would have quantifiable genital HIV-1 RNA levels. Based on this assumption, 31 cases would allow $90 \%$ power to detect a $0.6 \log _{10}$ copies/swab difference in vaginal HIV-1 RNA levels using a two-sided hypothesis test at $\alpha=0.05$. We have observed reductions in vaginal HIV-1 RNA greater than $0.6 \log _{10}$ copies/swab with successful treatment of $T$. vaginalis in studies of ART-naïve women [7].

The lower limit for linear quantitation for this assay was 100 copies/ml, which corresponds to 100 copies/ swab (swabs were placed in $1 \mathrm{ml}$ of freezing media). Because the majority of vaginal HIV-1 RNA levels were below 100 copies/ml even at the time of $T$. vaginalis infection, we followed our pre-specified alternative analysis plan, which dichotomized the outcome (vaginal HIV1 RNA) as detectable versus undetectable (< 100 copies/ $\mathrm{ml}$ ). Analyses were performed using SPSS 13.0 (SPSS Inc., Chicago, Illinois, USA) and STATA 9 (StataCorp, College Station, Texas, USA). The primary analysis utilized logistic regression with generalized estimating equations with an exchangeable correlation matrix to compare the presence of detectable HIV-1 RNA in vaginal secretions across the three visits, using the pre-infection visit as the baseline.

Our analysis plan included adjustment for number of months since ART initiation in all models, because increasing duration since ART initiation would be expected to be associated with greater levels of viral suppression, particularly during the first six months of treatment. We then considered adjustment for other potential confounding factors. Adjustment variables considered were adherence to ART (measured by visual analogue scale [VAS], pill count, or pharmacy refill timing), hormonal contraceptive use (use of oral contraceptives, Norplant or depot medroxyprogesterone acetate), presence of concurrent BV, vaginal washing (none, water only, water and soap), and week of the menstrual cycle (week 1-3, week 4 and 5, amenorrheic). We used two approaches to limit the number of potential confounding factors to include in the final model. First, we assessed the change across the three visits for each potential confounding variable, and second, we assessed the association between each variable and the outcome. In the final adjusted model, we only included variables that differed significantly across the three visits or were significantly related to the outcome $(\mathrm{p}=0.1)$.

\section{Results}

Between March 2004 and December 2008, 147 women enrolled in the ART cohort. Of these, 41 acquired T. vaginalis infection (incidence, 5.8 per 100 personyears). Ten women were excluded from these analyses.
Three did not receive treatment for $T$. vaginalis infection in our clinic because they did not return for results. These women were found to have no $T$. vaginalis present at later examinations. Two women had concurrent cervical infections, and two were lost to follow-up. We also excluded three women who were missing vaginal HIV-1 RNA data (2 at the pre-infection visit and 1 at the infection visit). Thirty-one women were included in the final analysis (Table 1). Their median age was 36 years (interquartile range [IQR] 31 - 38). At ART initiation, the majority were classified as WHO stage 3 or 4 (65\%). The median time from ART initiation to the pretrichomoniasis visit was 10.3 months, IQR (3.6-19.0). Thirty (97\%) women remained on first-line ART at the time of their first visit contributing to this analysis, while one woman had changed to a second-line regimen consisting of didanosine, zidovudine, and lopinavir/ritonavir 7 months prior to her infection episode.

The number of women with detectable vaginal HIV-1 RNA before, during, and after T. vaginalis infection was 4 (13\% [95\% confidence interval \{CI\} 4\% - 30\%]), 4 (13\% [95\% CI 4\% - 30\%]), and 5 (16\% [95\% CI 5\% - 34\%]), respectively. For women with detectable vaginal HIV-1 RNA, the median HIV-1 RNA levels before, during, and after $T$. vaginalis infection were 1438 (range 100 - 7223) copies/swab, 451 (range 105 - 928) copies/swab and 770 (range 105 - 29675) copies/swab respectively. Of the eight women with detectable vaginal HIV-1 RNA, one woman had detectable HIV-1 RNA at all three visits, three had detectable HIV-1 RNA at two visits and the other four had detectable HIV-1 RNA at only one visit.

Compared to the pre-infection visit, we were unable to detect differences in genital HIV-1 RNA either during infection $(\mathrm{p}=0.96)$ or following successful treatment $(\mathrm{p}=$ 0.81 ; Table 2). The results were similar after adjusting for potential confounding factors, in sensitivity analyses excluding 5 visits where sperm was detected in genital secretions, and in analyses excluding the participant on second-line ART (data not shown).

\section{Discussion}

Longitudinal sample collection in this study allowed us to compare genital HIV-1 shedding before, during, and after T. vaginalis infection. Among women receiving ART, we could detect no differences in HIV-1 RNA before versus during $T$. vaginalis infection. In addition, we were unable to detect differences in HIV-1 RNA after treatment of vaginal trichomoniasis in this population. Two thirds of the women in this study had undetectable genital HIV-1 shedding before, during, and after an episode of trichomoniasis.

In light of increasing global interest in the secondary HIV-1 prevention benefits of ART [18], it is important to understand whether factors suspected of increasing 
Table 1 Baseline characteristics of the 31 participants at the pre-infection visit

\begin{tabular}{|c|c|}
\hline Characteristic & $\begin{array}{r}\text { Median (IQR) or Number } \\
\text { (percent) }\end{array}$ \\
\hline \multicolumn{2}{|l|}{ Demographics } \\
\hline Age (years) & $36(31-38)$ \\
\hline Education (years) & $7(7-8)$ \\
\hline Pregnant & $1(3.2)$ \\
\hline Hormonal contraceptive method & $7(22.6)$ \\
\hline OCP & $1(3.2)$ \\
\hline DMPA & $4(12.9)$ \\
\hline Norplant & $2(6.5)$ \\
\hline \multicolumn{2}{|l|}{ Risk Behavior } \\
\hline $\begin{array}{l}\text { Number of partners in the last } \\
\text { week }\end{array}$ & $0(0-1)$ \\
\hline $\begin{array}{l}\text { Frequency of intercourse in the } \\
\text { last week }\end{array}$ & $0(0-2)$ \\
\hline $\begin{array}{l}\text { Percent condom use in the last } \\
\text { week }^{\mathrm{a}}\end{array}$ & $100(75-100)$ \\
\hline \multicolumn{2}{|l|}{ Clinical } \\
\hline \multicolumn{2}{|l|}{ WHO HIV staging at ART initiation } \\
\hline Stage I & $3(9.7)$ \\
\hline Stage II & $8(25.8)$ \\
\hline Stage III & $17(54.8)$ \\
\hline Stage IV & $3(9.7)$ \\
\hline \multicolumn{2}{|l|}{ CD4 lymphocyte count (cells/ml) } \\
\hline At start of antiretroviral therapy & $126(68-159)$ \\
\hline Pre-infection visit ${ }^{\mathrm{b}}$ & $241(161-292)$ \\
\hline $\begin{array}{l}\text { On stavudine, lamivudine, and } \\
\text { nevirapine }^{c}\end{array}$ & $30(96.7)$ \\
\hline Time since ART initiation (months) & $10.3(3.6-19.0)$ \\
\hline \multicolumn{2}{|l|}{ ART adherence in the past month } \\
\hline On-time refills ${ }^{d}$ & $27(87.1)$ \\
\hline Pill count adherence $\geq 95 \%$ & $21(67.7)$ \\
\hline
\end{tabular}

$\mathrm{IQR}$, interquartile range.

a Among 15 women who reported sexual intercourse in the last week.

${ }^{b}$ CD4 count at the pre-infection visit or nearest visit prior to infection was used.

' One woman was on a second-line regimen consisting of lopinavir/ritonavir, didanosine, and zidovudine.

${ }^{d}$ Late refills were defined as occurring $>48$ hours after a refill was due.

infectivity in ART-naïve individuals also do so in ARTtreated individuals, and thus may be likely to contribute to increased risk of transmission by those receiving treatment. Prior studies have demonstrated that sexually transmitted infections (STIs) are associated with higher genital
HIV-1 viral loads in women $[7,16,17,19]$. However, few studies have examined the effect of STIs or their treatment on genital HIV-1 shedding among women taking ART. Kissinger et al. examined the effect of treating $T$. vaginalis infection on vaginal HIV-1 RNA among ART-naïve and ART-treated HIV-1 positive women [20]. They found that treatment of trichomoniasis was associated with a significant reduction in HIV-1 RNA at 3 months post treatment (odds ratio $0.34,95 \% \mathrm{CI} 0.12-0.92 ; \mathrm{p}=0.03$ ). In addition, compared to women not taking ART, women taking ART were less likely to have vaginal HIV-1 RNA shedding (odds ratio $0.25,95 \%$ CI 0.10-0.62, $\mathrm{p}=0.01$ ) Based on a prior study of genital HIV-1 shedding in the setting of treatment for T. vaginalis in ART-naïve women [7], it is possible that the significant reduction in HIV-1 RNA detection after trichomoniasis treatment observed by Kissinger et al. was driven by the participants who were not taking ART (45\%). The study by Kissinger and colleagues did not present results for the ART-treated subset of women separately, so it was not possible to directly compare with our findings. Our present results demonstrate that ART can maintain vaginal HIV-1 suppression in the majority of women even when $T$. vaginalis infection is present.

The results presented here parallel those from recently published data from the same cohort assessing the impact of cervical infections [21] and genital ulcer disease (GUD) on genital HIV-1 shedding [22]. In the cervicitis study, HIV-1 RNA was detected in cervical secretions of 30 women before, during, and after cervicitis at one (3.2\%), five $(16.1 \%)$, and three $(9.7 \%)$ visits, respectively. In the GUD study of 36 women, HIV-1 RNA was detected before, during and after GUD in cervical secretions from four (11\%), one (3\%) and six (17\%) women, respectively, and in vaginal secretions from three $(8 \%)$, four $(11 \%)$ and four (11\%) women, respectively. Our present findings add to an expanding evidence base showing that ART generally maintains low or undetectable genital HIV-1 levels even in the presence of STIs.

There were limitations to this study. The sample size was initially calculated based on an assumption that more than half of women would have detectable genital HIV-1 RNA, which would have permitted us to compare the average HIV-1 RNA concentrations at different time points. Since most women actually had undetectable

Table 2 Vaginal HIV-1 RNA detection before, during, and after vaginal trichomoniasis in 31 women

\begin{tabular}{llllll}
\hline Visit & $\mathbf{N}(\%)$ & aOR $^{\mathbf{a}}(\mathbf{9 5} \% \mathrm{Cl})$ & P-value & aOR ${ }^{\text {b }}$ (95\% Cl) & P-value \\
\hline Pre-infection visit & $4(13 \%)$ & $1.0($ ref $)$ & & $1.0($ ref $)$ & \\
Infection visit & $4(13 \%)$ & $0.97(0.30-3.12)$ & $P=0.96$ & $1.41(0.23-8.79)$ & $P=0.71$ \\
Post-infection visit & $5(16 \%)$ & $1.19(0.28-5.05)$ & $P=0.81$ & $0.68(0.13-3.45)$ & $P=0.64$ \\
\hline
\end{tabular}

aOR, adjusted odds ratio; $95 \% \mathrm{Cl}, 95 \%$ confidence interval.

${ }^{a}$ Adjusted for duration on ART.

${ }^{\mathrm{b}}$ Adjusted for BV, late refill, hormonal contraception (yes/no), week of menstrual cycle and duration on ART. 
vaginal HIV-1 RNA, we instead used a bivariate outcome based on the presence or absence of vaginal HIV-1 RNA above the threshold for linear quantitation. While this limited the power of our analyses, the results remain useful, as they demonstrate that there were not large increases in either detection or quantity of vaginal HIV-1 RNA associated with episodes of $T$. vaginalis infection. A post hoc power calculation shows that with a sample size of 31 , we had $80 \%$ power to detect a 5 -fold increase in genital HIV-1 RNA detection with $T$. vaginalis infection. A second limitation is that the diagnosis of trichomoniasis by wet mount has limited sensitivity as it relies on visualization of motile protozoa. Because this method is relatively inexpensive, it is still highly relevant in resourceconstrained settings such as our study site. A third limitation was the choice to measure only vaginal viral loads. In an earlier study of ART-naïve women, we found that vaginal HIV-1 RNA levels decrease after treatment of T. vaginalis infection [7]. Our objective in the present study was to determine if the effect was the same in ARTtreated women. Although vaginal secretions are probably the most relevant sample type for a study of genital HIV-1 shedding and T. vaginalis infection, we acknowledge that we cannot rule out increases in cervical HIV-1 shedding in women with trichomoniasis. An additional limitation is that these data may not be generalizable to women on other ART regimens. This is particularly relevant in the case of protease inhibitors, which have lower penetration of the genital tract compared to non-nucleoside reversetranscriptase inhibitors (NNRTIs). However, because NNRTIs are extensively prescribed in first-line regimens throughout the world [12], our findings should have broad applicability.

\section{Conclusion}

In conclusion, we found that detection of vaginal HIV-1 RNA during ART was uncommon at visits before, during and after T. vaginalis infection. These findings suggest that the powerful effect of ART on genital HIV-1 shedding may lessen the potentiating effects of vaginal infections on HIV-1 transmission risk.

\section{Acknowledgements}

We thank the clinic, laboratory and administration staff in Mombasa for their important contribution to this study, the Mombasa Municipal Council for providing clinical space, Coast Provincial General Hospital for provision of laboratory space, and the Director of the Kenya Medical Research Institute for permission to publish this paper. Special thanks go to the women who participated in this study.

This research was supported by the National Institutes of Health (grant R01 Al58698) and Fogarty International Center (NIH 5D43-TW000007 to L.N.M., S. M.G. and R.G). Additional support for the Mombasa Field Site was received from the University of Washington Center for AIDS Research (CFAR), an NIH funded program (P30 Al027757) which is supported by the following $\mathrm{NIH}$ Institutes and Centers (NIAID, NCl, NIMH, NIDA, NICHD, NHLBI, NCCAM). The funders had no role in study design, data collection and analysis, decision to publish, or preparation of the manuscript.
Presented in part at the $17^{\text {th }}$ Conference on Retroviruses and Opportunistic Infections (CROI 2010); $16-19^{\text {th }}$ February, 2010, San Francisco (poster 1023).

\section{Author details}

${ }^{1}$ Department of Epidemiology, Box 357236, University of Washington, Seattle, Washington 98195, USA. ²Department of Medicine, Box 356420, University of Washington, Seattle, Washington 98195, USA. ${ }^{3}$ Department of Global Health, Box 358116, University of Washington, Seattle, Washington 98195, USA. ${ }^{4}$ Department of Biostatistics, Box 357232, University of Washington, Seattle, Washington 98195, USA. ${ }^{5}$ Department of Medical Microbiology, University of Nairobi, P.O. Box 30197-00100, Nairobi, Kenya. ${ }^{6}$ Kenya Medical Research Institute, P.O. Box 230-80108, Kilifi, Kenya. ${ }^{7}$ Coast Provincial General Hospital, P.O. Box 90231, Mombasa, Kenya. ${ }^{8}$ Division of Human Biology, Fred Hutchinson Cancer Research Center, P.O. Box 19024, Seattle, Washington 98109, USA

\section{Authors' contributions}

RSM, BAR, NP, KM, WJ, and JONA. conceived the question and designed the study. RSM obtained funding for the study. LNM, RSM, SMG, BAR, JO and RG participated in collection and interpretation of the data. LNM, BAR and SMG conducted the data analyses. All authors participated in preparation of the manuscript and approved the final draft for submission.

\section{Competing interests}

The authors declare that they have no competing interests.

Received: 16 September 2010 Accepted: 3 November 2011 Published: 3 November 2011

\section{References}

1. WHO: AIDS Epidemic Update. 2009 [http://data.unaids.org/pub/report/ 2009/jc1700_epi_update_2009_en.pdf].

2. Baeten JM, Overbaugh J: Measuring the infectiousness of persons with HIV-1: opportunities for preventing sexual HIV-1 transmission. Curr HIV Res 2003, 1:69-86.

3. Coombs RW, Reichelderfer PS, Landay AL: Recent observations on HIV type-1 infection in the genital tract of men and women. Aids 2003, 17:455-480.

4. Graham SM, Holte SE, Peshu NM, Richardson BA, Panteleeff DD, Jaoko WG Ndinya-Achola JO, Mandaliya KN, Overbaugh JM, McClelland RS: Initiation of antiretroviral therapy leads to a rapid decline in cervical and vaginal HIV-1 shedding. Aids 2007, 21:501-507.

5. Neely MN, Benning L, Xu J, Strickler HD, Greenblatt RM, Minkoff $H$, Young M, Bremer J, Levine AM, Kovacs A: Cervical shedding of HIV-1 RNA among women with low levels of viremia while receiving highly active antiretroviral therapy. J Acquir Immune Defic Syndr 2007, 44:38-42.

6. Hobbs MM, Kazembe P, Reed AW, Miller WC, Nkata E, Zimba D, Daly CC, Chakraborty H, Cohen MS, Hoffman I: Trichomonas vaginalis as a cause of urethritis in Malawian men. Sex Transm Dis 1999, 26:381-387.

7. Wang CC, McClelland RS, Reilly M, Overbaugh J, Emery SR, Mandaliya K, Chohan B, Ndinya-Achola J, Bwayo J, Kreiss JK: The effect of treatment of vaginal infections on shedding of human immunodeficiency virus type 1. J Infect Dis 2001, 183:1017-1022.

8. Price MA, Zimba D, Hoffman IF, Kaydos-Daniels SC, Miller WC, Martinson F, Chilongozi D, Kip E, Msowoya E, Hobbs MM, et al: Addition of treatment for trichomoniasis to syndromic management of urethritis in Malawi: a randomized clinical trial. Sex Transm Dis 2003, 30:516-522.

9. Sadiq ST, Taylor S, Kaye S, Bennett J, Johnstone R, Byrne P, Copas AJ, Drake SM, Pillay D, Weller I: The effects of antiretroviral therapy on HIV-1 RNA loads in seminal plasma in HIV-positive patients with and without urethritis. Aids 2002, 16:219-225.

10. Baeten JM, Kahle E, Lingappa JR, Coombs RW, Delany-Moretlwe S, NakkuJoloba E, Mugo NR, Wald A, Corey L, Donnell D, et al: Genital HIV-1 RNA Predicts Risk of Heterosexual HIV-1 Transmission. Sci Transl Med 3:77ra29.

11. Martin HL Jr, Nyange PM, Richardson BA, Lavreys L, Mandaliya K, Jackson DJ, Ndinya-Achola JO, Kreiss J: Hormonal contraception, sexually transmitted diseases, and risk of heterosexual transmission of human immunodeficiency virus type 1. J Infect Dis 1998, 178:1053-1059.

12. WHO: Scaling up Antiretroviral Therapy in Resource-Limited Settings: Treatment Guidelines for a Public Health Approach. 2003 [http://www. who.int/hiv/pub/prev_care/en/arvrevision2003en.pdf]. 
13. WHO: Guidelines for the management of sexually transmitted infections. 2003 [http://www.who.int/hiv/pub/sti/en/STIGuidelines2003.pdf]

14. Panteleeff D, Emery S, Richardson BA, Rousseau C, Benki S, Bodrug S, Kreiss JK, Overbaugh J: Validation of performance of the Gen-Probe human immunodeficiency virus type 1 viral load assay with genital swabs and breast milk samples. J Clin Microbiol 2002, 40:3929-3937.

15. Nugent RP, Krohn MA, Hillier SL: Reliability of diagnosing bacterial vaginosis is improved by a standardized method of gram stain interpretation. J Clin Microbiol 1991, 29:297-301.

16. Ghys PD, Fransen K, Diallo MO, Ettiegne-Traore V, Coulibaly IM, Yeboue KM, Kalish ML, Maurice C, Whitaker JP, Greenberg AE, Laga M: The associations between cervicovaginal HIV shedding, sexually transmitted diseases and immunosuppression in female sex workers in Abidjan, Cote d'Ivoire. Aids 1997, 11:F85-93.

17. Tanton C, Weiss HA, Le Goff J, Changalucha J, Rusizoka M, Baisley K, Everett D, Ross DA, Belec L, Hayes RJ, Watson-Jones D: Correlates of HIV-1 Genital Shedding in Tanzanian Women. PLoS One 6:e17480.

18. Cohen MS, Gay C, Kashuba AD, Blower S, Paxton L: Narrative review: antiretroviral therapy to prevent the sexual transmission of HIV-1. Ann Intern Med 2007, 146:591-601.

19. McClelland RS, Wang CC, Mandaliya K, Overbaugh J, Reiner MT, Panteleeff DD, Lavreys L, Ndinya-Achola J, Bwayo JJ, Kreiss JK: Treatment of cervicitis is associated with decreased cervical shedding of HIV-1. Aids 2001, 15:105-110.

20. Kissinger $P$, Amedee A, Clark RA, Dumestre J, Theall KP, Myers L, Hagensee ME, Farley TA, Martin DH: Trichomonas vaginalis treatment reduces vaginal HIV-1 shedding. Sex Transm Dis 2009, 36:11-16.

21. Gitau RW, Graham SM, Masese LN, Overbaugh J, Chohan V, Peshu N, Richardson BA, Jaoko W, Ndinya-Achola JO, McClelland RS: Effect of acquisition and treatment of cervical infections on HIV-1 shedding in women on antiretroviral therapy. Aids 24:2733-2737.

22. Graham SM, Masese L, Gitau R, Richardson BA, Mandaliya K, Peshu N, Jaoko W, Ndinya-Achola J, Overbaugh J, McClelland RS: Genital ulceration does not increase HIV-1 shedding in cervical or vaginal secretions of women taking antiretroviral therapy. Sex Transm Infect 87:114-117.

\section{Pre-publication history}

The pre-publication history for this paper can be accessed here: http://www.biomedcentral.com/1471-2334/11/307/prepub

doi:10.1186/1471-2334-11-307

Cite this article as: Masese et al: A prospective study of vaginal trichomoniasis and HIV-1 shedding in women on antiretroviral therapy. BMC Infectious Diseases 2011 11:307.

\section{Submit your next manuscript to BioMed Central and take full advantage of:}

- Convenient online submission

- Thorough peer review

- No space constraints or color figure charges

- Immediate publication on acceptance

- Inclusion in PubMed, CAS, Scopus and Google Scholar

- Research which is freely available for redistribution

Submit your manuscript at www.biomedcentral.com/submit 